ORIGINAL ARTICLE

\title{
A NOVEL MODEL FOR ORIENTATION OF LINEAR OPTICAL SATELLITE IMAGES BASED IN THE ADAPTATION OF THE ORBIT-ATTITUDE MODEL
}

\author{
Tiago Lima Rodrigues ${ }^{1}$ - ORCID: 0000-0002-3037-9037 \\ Marcela do Valle Machado² - ORCID: 0000-0002-0621-6932 \\ ${ }^{1}$ Universidade Federal do Paraná, Departamento de Geomática, Curitiba, Paraná, Brasil. \\ E-mail: tiagorodrigues@ufpr.br \\ ${ }^{2}$ Universidade Estadual Paulista Júlio de Mesquita Filho, Programa de Pós-Graduação em Ciências \\ Cartográficas, Presidente Prudente, São Paulo, Brasil. \\ E-mail: marcelavmachado@gmail.com
}

Received in 30 $0^{\text {th }}$ January 2019

Accepted in $10^{\text {th }}$ April 2019

\begin{abstract}
:
In this paper a novel model to orient a pushbroom linear optical satellite image is proposed. This one is based in the adaptation of the Orbit-Attitude model for use of the Modified UCL Kepler platform model. It has only the components of satellite position and velocity as unknowns. This implies not only the reduction of unknowns but also the elimination of initial adjustments of the orbit to estimate the polynomial parameters. In order to validate the model, four experiments were conducted using one HRC-CBERS 2B image. Two distributions of ground controls points (GCPs) were tested, 70 and 35 GCPs. A quantity of 43 check points (CPs) was used to analyze the planimetric accuracies of the orientations. For comparisons purpose the image was also oriented with platform model using $2^{\text {nd }}$ order polynomial. The results showed that the planimetric accuracy difference in the use of the two models is 4 and 6 centimeters in the two mentioned configurations of GCPs, respectively. However, the main advantage of applying the proposed model is the direct use of ephemeris without the necessity of interpolations and preadjustments, which makes the orientation process simpler.
\end{abstract}

Keywords: Linear optical satellite image, Orbit-Attitude Model, UCL Kepler platform model.

How to cite this article: RODRIGUES, T. L. and MACHADO, M V. A Novel Model for Orientation of Linear Optical Satellite Images Based in the Adaptation of the Orbit-Attitude Model. Bulletin of Geodetic Sciences, 25(3): e2019013, 2019. 


\section{Introduction}

The satellite images orientation is a necessary process to obtain spatial data, such as coordinates, areas, perimeters and distances values. Considering the mathematical modeling of satellite images provided for pushbroom linear array sensors, two classes of models are defined: the generalized models and rigorous models (Toutin 2004). While the first use polynomial functions, the second objective model the physical process of obtaining the images, usually using the principle of collinearity. According to Jacobsen (2007), the rigorous models propose results that are more accurate with greater flexibility in the amount and distribution of control points on the image. Within the context of rigorous models, there are two types of modeling: the PositionRotation model and the Orbit-Attitude model (Radhadevi, Sasikumar and Ramachandran 1994; Kim and Dowman 2006). The generalized models are exclusively used in the case of cut images or with some type of geometric correction previously made.

The Position-Rotation model uses only two Reference Systems: the Camera Reference System (CRS) and the Terrestrial Reference System (TRS). The rotation matrix, which aligns the two systems, depends only on the orientation angles $\omega, \phi$ e $\mathrm{k}$. It is noteworthy that these angles are different from the so-called attitude angles, since they have no physical sense (Kim and Dowman 2006). On the other hand, the Orbit-Attitude model uses the two systems mentioned above for the images orientation in addition to the Satellite Reference System (SRS) and the Orbit Reference System (ORS). Three rotation matrices are used which depends on the boresight angles, attitude angles and the position and velocity vectors. In this way, Kim and Dowman (2006) indicate that this model is in fact a physical model.

In mathematical modeling, regardless the rigorous model, a platform model has to be used to model the changes in the Exterior Orientation Parameters (EOP), since the image formation is dynamic, line-by-line. Each line is obtained separately in different instants. Different platform models have been developed over the years. The most known model is the $2^{\text {nd }}$ or $3^{\text {rd }}$ polynomial model (Gugan and Dowman 1988; Westin 1990; Orun and Natarajan 1994; Radhadevi, Sasikumar and Ramachandran 1994; Bang and Cho 2001; Kim and Dowman 2006; Medeiros and Tommaselli 2009; Marcato Júnior et al. 2011). However, Michalis and Dowman (2005) indicated that in the $2^{\text {nd }}$ order polynomial model, the $1^{\text {st }}$ order coefficients represent the components of velocity of the platform and the $2^{\text {nd }}$ order coefficients represent the components of acceleration. The platform model developed by the authors was called Kepler model and posteriorly UCL Kepler model (Michalis and Dowman 2008). Since the UCL Kepler platform model was developed to use coordinates referenced to the Geocentric Celestial Reference System (GCRS), Rodrigues et al. (2017) proposed a methodology for the use of coordinates referenced to a TRS. In this research, this platform model is going to called Modified UCL Kepler platform model.

Some examples of works development using these models to orient HRC CBERS-2B images can be cited. In Marcato Junior (2011) can be seen a bundle block adjustment of four images using Orbit-Attitude model in conjunction with a $2^{\text {nd }}$ order polynomial platform model. In Marcato Júnior et al. (2011) and Marcato Júnior and Tommaselli (2013) HRC and CCD images were orientated using the same models. This last combining Ground Control Points (GCPs) and Ground Control Lines (GCLs). Also in Rodrigues and Ferreira (2013), two HRC images were oriented using Position-Rotation model in conjunction with a $2^{\text {nd }}$ order polynomial platform model and original UCL Kepler platform model. In Rodrigues et al (2016) on-orbit geometric calibration of HRC sensor was performed using Position-Rotation model and Modified UCL Kepler platform model. 
Originally, the UCL Kepler platform model has been used along with the Position-Rotation rigorous model. In this paper we proposed a novel model based in the adaptation of the OrbitAttitude model for use of the Modified UCL Kepler platform model. The model has only the components of satellite position and velocity are unknowns. To evaluate its application, experiments using one HRC CBERS-2B image were performed and the planimetric accuracies were analyzed. For comparison, the image was also oriented using the Orbit-Attitude model in conjunction with the $2^{\text {nd }}$ order polynomial model platform. It is noteworthy that to use this last model is necessary a pre-adjustment, in order to estimate at least the polynomials parameters referred to the changes in the components of satellite velocity (Marcato et al. 2011). It is because these parameters must be considered fixed and without errors in the bundle adjustment since they are strongly correlated with the position parameters. The use of the proposed model does not require this pre-adjustment, which makes the process of orientation simpler.

\section{Rigorous Mathematical models}

The mathematical modelling to satellite image orientation can be based in collinearity principle. Thus, the collinearity equations modified for the linear array sensors are used, where $x_{c}$ coordinate of CRS is assumed as zero (Gugan and Dowman 1988). Furthermore, the platform model must be included in the exterior orientation to model the changes of EOP during image formation. In the section 2.1 the Orbit-Attitude model is explained. Posteriorly, in the section 2.2 the structure and characteristics of the original and Modified UCL Kepler platform model is presented and some of the works developed with the use of it are mentioned.

\subsection{Traditional Orbit-Attitude model}

The Orbit-Attitude model uses the CRS, SRS, ORS and a TRS system. The SRS is a dextrogyrous system fixed in the satellite with origin in its center of mass. The direction of axes is determined from the direction of the CRS axes, applying rotations in terms of the boresight angles $b_{x}, b_{y}$ and bz. The rotation matrix which aligns the CRS with the SRS is (Machado e Silva 2007):

$$
R_{C}^{P}=R_{Z}\left(b_{z}\right) R_{Y}\left(b_{Y}\right) R_{X}\left(b_{X}\right) .
$$

In order to make compatible the origins of the SRS with the CRS, it should be considered the translation vector $(d X, d Y, d Z)$ between the satellite center of mass and the Perspective Center (PC) of the sensor. If there is a GNSS (Global Navigation Satellite System) receiver on board the satellite providing state vector data, an additional vector of translations must be considered in order to make compatible the GNSS receiver antenna phase center with the satellite center of mass.

The ORS has the same origin of the SRS. However, the $x$ axes indicates the direction of motion of the satellite in orbit, the $z$ axes points to the Earth center of mass and the $y$ axis completes the dextrogyrous system. To perform the transformation from SRS to the ORS it should be applied a rotation matrix in terms of time-dependent platform attitude angles roll $(R)$, pitch $(P)$ and yaw $(\Psi)$. This matrix is given by (Jovanovic, Smyth and Zong 1999): 


$$
R_{P}^{O}(t)=R_{Z}(R(t)) R_{Y}(P(t)) R_{X}(\Psi(t))
$$

Finally, to transform from ORS to a TRS it should be applied a rotation matrix in terms of state vector components referred to PC of the sensor as follow (Jovanovic, Smyth and Zong 1999; Poli 2005):

$$
R_{O}^{T}(t)=\left[\begin{array}{lll}
\frac{V_{Z} X_{S} Z_{S}-Z_{S}^{2} V_{X}-V_{X} Y_{S}^{2}+X_{S} Y_{S} V_{Y}}{L_{P}^{2} L_{V}} & \frac{-Y_{S} V_{Z}+V_{Y} Z_{S}}{L_{V} L_{P}} & -\frac{X_{S}}{L_{P}} \\
\frac{V_{X} Y_{S} X_{S}-X_{S}^{2} V_{Y}-V_{Y} Z_{S}^{2}+Y_{S} Z_{S} V_{Z}}{L_{P}^{2} L_{V}} & \frac{-Z_{S} V_{X}+V_{Z} X_{S}}{L_{V} L_{P}} & -\frac{Y_{S}}{L_{P}} \\
\frac{V_{Y} Z_{S} Y_{S}-Y_{S}^{2} V_{Z}-V_{Z} X_{S}^{2}+X_{S} Z_{S} V_{X}}{L_{P}^{2} L_{V}} & \frac{-X_{S} V_{Y}+V_{X} Y_{S}}{L_{V} L_{P}} & -\frac{Z_{S}}{L_{P}}
\end{array}\right],
$$

where:

$$
\begin{aligned}
& L_{P}=\sqrt{X_{S}^{2}+Y_{S}^{2}+Z_{S}^{2}} \\
& L_{V}=\sqrt{V_{X}^{2}+V_{Y}^{2}+V_{Z}^{2}} .
\end{aligned}
$$

Considering the collinearity principle, the following formulation shows:

$$
\left[\begin{array}{c}
0 \\
y_{c_{i}} \\
-f
\end{array}\right]=\lambda_{i} R_{C}^{P^{T}}\left(R_{P}^{O}(t)^{T} R_{O}^{T}(t)^{T}\left[\begin{array}{c}
X_{i}-X_{S}(t) \\
Y_{i}-Y_{S}(t) \\
Z_{i}-Z_{S}(t)
\end{array}\right]-\left[\begin{array}{c}
d X \\
d Y \\
d Z
\end{array}\right]\right)
$$

Dividing the first and second equation obtained from Equation (6) by the third equation, the scale factor to the point $i\left(\lambda_{\mathrm{i}}\right)$ is canceled obtaining the modified collinearity equations. If $d X, d Y$ and $d Z$ are equal to zero it has:

$$
\begin{gathered}
0=-f \frac{r_{11}{ }^{\prime}\left(X_{i}-X_{S}(t)\right)+r_{12}{ }^{\prime}\left(Y_{i}-Y_{S}(t)\right)+r_{13}{ }^{\prime}\left(Z_{i}-Z_{S}(t)\right)}{r_{31}{ }^{\prime}\left(X_{i}-X_{S}(t)\right)+r_{32}{ }^{\prime}\left(Y_{i}-Y_{S}(t)\right)+r_{33^{\prime}}\left(Z_{i}-Z_{S}(t)\right)}, \\
y_{c}=-f \frac{r_{21}{ }^{\prime}\left(X_{i}-X_{S}(t)\right)+r_{22}{ }^{\prime}\left(Y_{i}-Y_{S}(t)\right)+r_{23}{ }^{\prime}\left(Z_{i}-Z_{S}(t)\right)}{r_{31}{ }^{\prime}\left(X_{i}-X_{S}(t)\right)+r_{32}{ }^{\prime}\left(Y_{i}-Y_{S}(t)\right)+r_{33}{ }^{\prime}\left(Z_{i}-Z_{S}(t)\right)},
\end{gathered}
$$

where $r_{11}{ }^{\prime}, \ldots, r_{33}{ }^{\prime}$ are the components of rotation matrix:

$$
R(t)=R_{C}^{P^{T}} R_{P}^{O}(t)^{T} R_{O}^{T}(t)^{T}
$$


The most common platform model used for this model is the time-depend $2^{\text {nd }}$ order polynomial function as shown in Kim and Dowman (2006) and Marcato Junior et al. (2011):

$$
\begin{aligned}
& X_{s}=X_{0}+a_{1} t+b_{1} t^{2}, \\
& Y_{s}=Y_{0}+a_{2} t+b_{2} t^{2}, \\
& Z_{s}=Z_{0}+a_{3} t+b_{3} t^{2}, \\
& V_{x}=V_{x 0}+a_{4} t+b_{4} t^{2}, \\
& V_{y}=V_{y 0}+a_{5} t+b_{5} t^{2}, \\
& V_{z}=V_{z 0}+a_{6} t+b_{6} t^{2}, \\
& \mathrm{R}=\mathrm{R}_{0}+a_{7} t+b_{7} t^{2}, \\
& P=P_{0}+a_{8} t+b_{8} t^{2}, \\
& \Psi=\Psi_{0}+a_{9} t+b_{9} t^{2},
\end{aligned}
$$

where $X_{0}, Y_{0}, Z_{0}, V_{X_{0}}, V_{Y_{0}}, V_{Z_{0}}$ are the components of PC position and velocity referred to a TRS at the acquisition time of the first line; $R_{0}, P_{0}$ and $\Psi_{0}$ represent the attitude angles at the acquisition time of the first line; $a_{1}, b_{1}, \ldots, a_{9}, b_{9}$ are the polynomial coefficients and; $t$ is the time. It is noteworthy that according to Marcato Júnior et al. (2011) the velocity parameters are strongly correlated to the position parameters, because the velocity is calculated by the difference of position in a given time interval. Thus, $V_{x 0}, a_{4}, b_{4}, V_{y_{0}}, a_{5}, b_{5}, V_{z 0}, a_{6}$ and $b_{6}$ parameters should be firstly calculated. Later in the adjustment, their values must be considered fixed and without error.

\subsection{UCL Kepler Model}

From the idea that the satellite position can be propagated by a $2^{\text {nd }}$ order polynomial function, Michalis and Dowman (2005) developed a platform model based in the theory of Uniformly Accelerated Motion (UAM). The model was firstly called Kepler model and then called UCL Kepler model as can be seen in (Michalis and Dowman 2008b). In this model, the $1^{\text {st }}$ and $2^{\text {nd }}$ order polynomial coefficients of position are replaced respectively by the components of velocity and accelerations. Additionally the accelerations are calculated from components of positions and velocities using the theory of Two-body Problem (Seeber 2003). It has then: 


$$
\begin{gathered}
X_{S}(t)=X_{0}+u_{x} \tau-\frac{G M \cdot X_{0} \cdot \tau^{2}}{2 \cdot\left(X_{0}{ }^{2}+Y_{0}{ }^{2}+Z_{0}{ }^{2}\right)^{3 / 2}}, \\
Y_{S}(t)=Y_{0}+u_{y} \tau-\frac{G M \cdot Y_{0} \cdot \tau^{2}}{2 \cdot\left(X_{0}{ }^{2}+Y_{0}{ }^{2}+Z_{0}{ }^{2}\right)^{3 / 2}}, \\
Z_{S}(t)=Z_{0}+u_{z} \tau-\frac{G M \cdot Z_{0} \cdot \tau^{2}}{2 \cdot\left(X_{0}{ }^{2}+Y_{0}{ }^{2}+Z_{0}{ }^{2}\right)^{3 / 2}}, \\
\omega=\omega_{0}, \\
\varphi=\varphi_{0}, \\
\kappa=\kappa_{0},
\end{gathered}
$$

where $X_{0}, Y_{0}, Z_{0}$ are the components of $P C$ position referred to a Geocentric Celestial Reference System (GCRS) at the acquisition time of the first line; $u_{x}, u_{y}, u_{z}$ are the components of PC velocity referred to a GCRS at the acquisition time of the first line; $t$ is the time and; $G M$ is the geocentric gravitational constant (particular for each TRS).

In Michalis and Dowman (2005), can be observed that the orientation angles are considered invariable in platform model. However, this can be changed according to the operation mode of each satellite. An example for PRISM-ALOS images can be seen in Dowman, Michalis and Li (2011). Another point is that this platform model was developed and used in conjunction with Position-Rotation models.

An important consideration is that Keplerian motion is maintained along the acquisition time of images. For this reason, the object space coordinates should be referred to a GCRS. Thus, before the orientation, the coordinates of Ground Control Points (GCPs) and Check Points (CPs), obtained originally in a TRS, must be transformed to coordinates referred to a GCRS. In order to avoid this procedure, Rodrigues et al. (2017) modified the original UCL Kepler platform model for the use of Two-bodies problem in a TRS, inserting term in function of angular velocity of Earth's rotation. Once the time interval for obtaining the HRC-CBERS-2B images is relatively small ( $\sim 4 s)$, the components of Precession, Nutation and pole displacement can be disregarded without prejudice. More details about the mathematical development can be seen in Leick (2004) and Rodrigues et al. (2017). In this research this model is going to called Modified UCL Kepler platform model. Application examples with the original UCL Kepler platform model can be seen in Dowman and Michalis (2003) with ASTER images; Michalis and Dowman (2004), Michalis (2005), Michalis and Dowman (2006), Michalis and Dowman (2008a) with HRS SPOT 5 images; Michalis and Dowman (2008b) with CARTOSAT I images; Dowman, Michalis and Li (2011), Michalis and Dowman (2010); Rodrigues and Ferreira (2013) with HRC CBERS 2B images.

\section{Methodology}

In this study, in order to validate the proposed model, one HRC-CBERS $2 B$ image was used. HRC was one of the sensors on board the satellite CBERS 2B and operated in the spectral range of 0.5 to $0.8 \mu \mathrm{m}$. The images were generated in the panchromatic band, with $2.7 \mathrm{~m}$ of spatial resolution, covering $27 \times 27 \mathrm{~km}$ on the surface. Table 1 presents the main characteristics of HRC sensor. 
Table 1: Main characteristics of HRC sensor (Inpe 2014; Marcato Junior and Tommaselli 2013).

\begin{tabular}{c|c}
\hline Characteristic & Information \\
\hline Nominal focal length & $3398 \mathrm{~mm}$ \\
\hline Detector size in CCD & $0.010 \mathrm{~mm}$ \\
\hline Time integration of CCD line $(d t)$ & $0.000345 \mathrm{~s} /$ line \\
\hline Number of columns in image & 12246 columns \\
\hline
\end{tabular}

The focal plane of the HRC sensor was formed by three linear arrays CCD chips and there are misalignments between the left and right CCD chips with the middle CCD chip (Figure 1). This creates a difference in the moment of obtaining the sub-images provided by these chips, causing a systematic error in the process of formation of final image with 12246 columns. For this reason, in experiments performed by Marcato Junior (2011), Marcato Júnior et al. (2011), Marcato Júnior and Tommaselli (2013) and Rodrigues and Ferreira (2013), is possible to verify a decrease of accuracy in North direction. Additionally, the planimetric resulting accuracies presented larger than 1 pixel $(2.7 \mathrm{~m})$. This is relates to the difficulty of obtaining an accurate measurement of the points in the images due to poor radiometric quality. On-orbit geometrics calibrations of HRC sensor were performed in Zhang and Zheng (2012) and Rodrigues et al. (2016). In this last work the values of misalignments between the CCD chips were estimated at a given epoch.

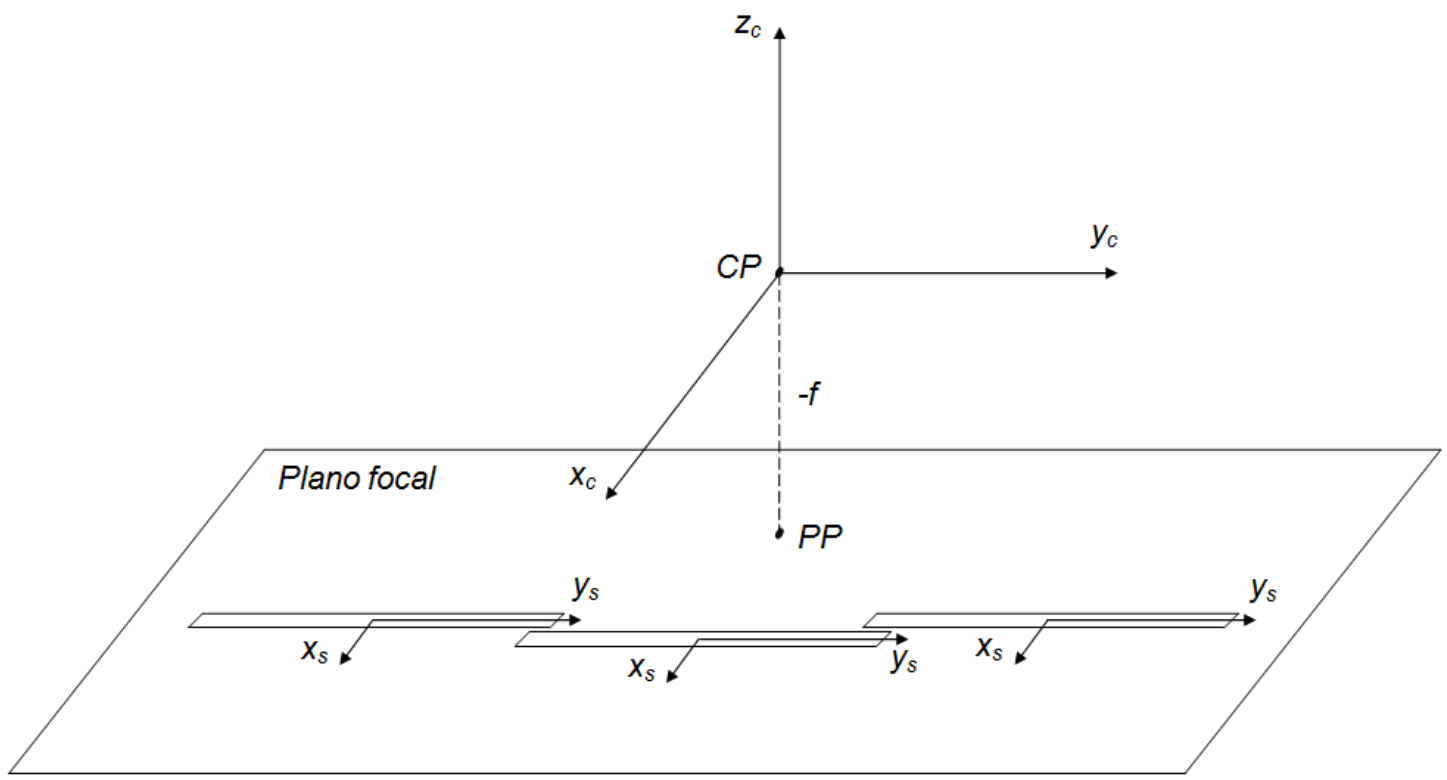

Figure 1: HRC sensor focal plane with three linear array CCD chips.

Source: Rodrigues et al. (2016).

For the experiments one test field were chosen. This one is part of the Distrito Federal in Brazil Central Region. The orbit/path for this image was 157_E_120_5 and the date is 14/09/2009. For the experiments, $70 \mathrm{GCPs}$ and $43 \mathrm{CPs}$ were extracted from digital topographic map in scale 1: 2000 generated by SICAD-DF project. The collection of GCPs and CPs occurred manually. The image observations standard deviation was considered of 3 pixels $(0.030 \mathrm{~mm})$. The used image has level 1 processing (only radiometric correction) and the ephemerides are referred to TRS WGS-84 (G1150). In order to extract the altimetric components of the GCPs and CPs were used 
Digital Terrain models (DTM) ASTER GDEM, with $30 \mathrm{~m}$ of spatial resolution, planimetrically referred to the WGS-84 (G1150) and vertically referred to the EGM 96 global geoid. The overall accuracy of the ASTER GDEM, on a global basis, can be taken to be approximately 20 meters at 95\% confidence (ASTER GDEM VALIDATION TEAM, 2009). The distribution of GCPs and CPS on the image in experiments can be seen in Figure 2.

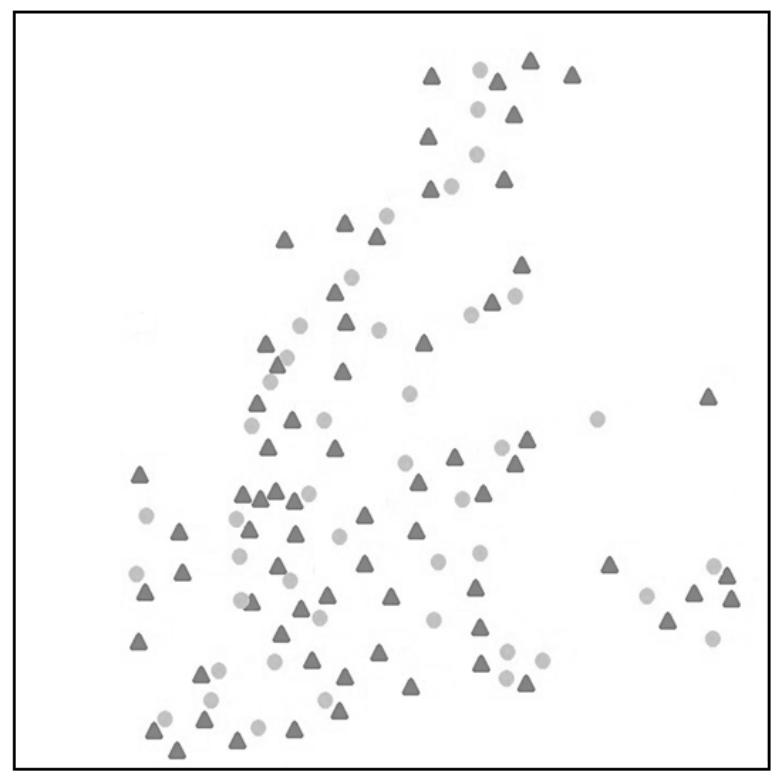

(a)

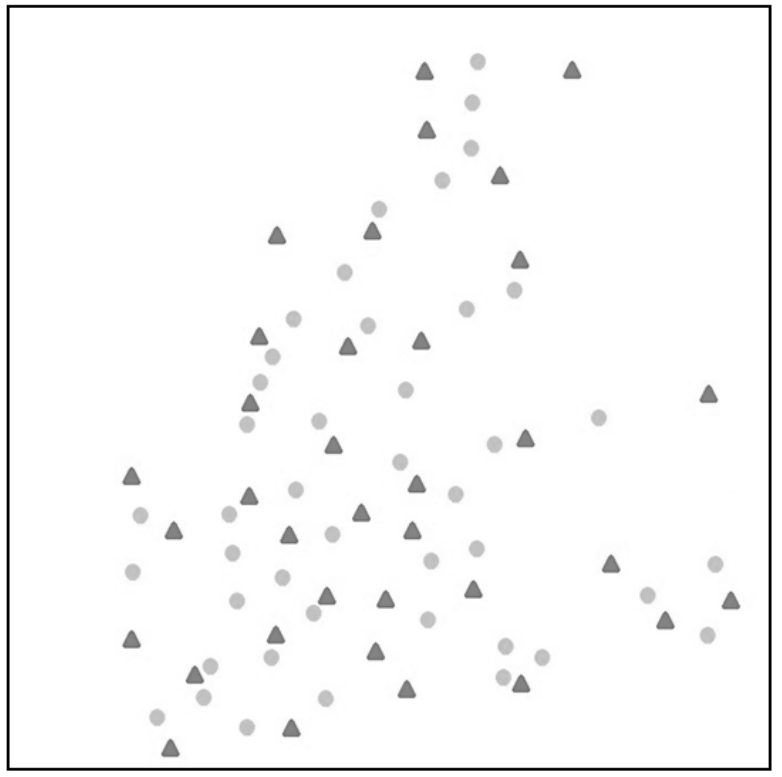

(b)

\section{- Ground Control Points Check Points}

Figure 2: GCPs and CPs distribution in experiment 1 and 2 (a), and in experiment 3 and 4 (b).

A set of four experiments was defined to analyze the use of the proposed model with the Modified UCL Kepler and $2^{\text {nd }}$ order polynomial platform models, using different amount of GCPs on the images. Table 2 presents the characteristics of the experiments.

Table 2: Characteristics of the experiments.

\begin{tabular}{c|c}
\hline Experiment & Characteristic \\
\hline 1 & Modified UCL Kepler model +70 GCPs/43 CPs \\
\hline 2 & $2^{\text {nd }}$ order polynomial model +70 GCPs/43 CPs \\
\hline 3 & Modified UCL Kepler model +35 GCPs/43 CPs \\
\hline 4 & $2^{\text {nd }}$ order polynomial model +35 GCPs/43 CPs \\
\hline
\end{tabular}




\subsection{Mathematical modelling}

The rigorous Orbit-Attitude model was used to the images orientation. Since the values of the translations vector $(d X, d Y, d Z)$ between the satellite center of mass and the PC of the sensor are not known, they were considered equals to zero in Equation (6). Thus, the collinearity equation in form of Equations (7) e (8) was used. In this study, two platform models were tested. The Modified UCL Kepler model and the $2^{\text {nd }}$ order polynomial model (Equation (10)). In both platform models, the angles $R_{0}$ and $P_{0}$ were considered invariable during the time of image formation. On the other hand, the angle $\Psi_{0}$ was considered variable and propagated with a $2^{\text {nd }}$ order polynomial function. This in view of the lateral motion of the satellite CBERS 2B denominates crab movement (Machado e Silva 2007).

In the case of Modified UCL Kepler platform model, since the theory of UAM has been considered, an adaptation was made, so that the velocity components could be estimated by the accelerations components. Thus, the adapted platform model is:

$$
\begin{gathered}
X_{S}(t)=X_{0}+V_{0_{X}} t+\left[-\frac{G M \cdot X_{0}}{2 \cdot r^{3}}+\omega_{t}^{2} X_{0}+2 \Omega_{t} V_{0_{Y}}\right] \cdot t^{2}, \\
Y_{S}(t)=Y_{0}+V_{0_{Y}} t+\left[-\frac{G M \cdot Y_{0}}{2 \cdot r^{3}}+\omega_{t}^{2} Y_{0}+2 \Omega_{t} V_{0_{X}}\right] \cdot t^{2}, \\
Z_{s}(t)=Z_{0}+V_{0_{Z}} t-\frac{G M \cdot Z_{0}}{2 \cdot r^{3}} \cdot t^{2}, \\
V_{X}(t)=V_{0_{X}}+\left[-\frac{G M \cdot X_{0}}{2 \cdot r^{3}}+\omega_{t}^{2} X_{0}+2 \Omega_{t} V_{0_{Y}}\right] \cdot t, \\
V_{Y}(t)=V_{0_{Y}}+\left[-\frac{G M \cdot Y_{0}}{2 \cdot r^{3}}+\omega_{t}^{2} Y_{0}+2 \Omega_{t} V_{0_{X}}\right] \cdot t, \\
V_{Z}(t)=V_{0_{Z}}-\frac{G M \cdot Z_{0}}{2 \cdot r^{3}} \cdot t \\
R=R_{0}, \\
P=P_{0}, \\
\Psi=\Psi_{0}+d_{1} t+d_{2} t^{2},
\end{gathered}
$$

with:

$$
r=\sqrt{X_{0}^{2}+Y_{0}^{2}+Z_{0}^{2}}
$$

where $d_{1}$ and $d_{2}$ are the polynomials coefficients of the $\Psi_{0}$ variation; $\Omega_{t}$ is the modulus of the angular velocity of Earth's rotation (equals to $7292115 \times 10^{-11} \mathrm{rad} \mathrm{s}^{-1}$ in TRS WGS-84 G1150) and; $G M$ is the geocentric gravitational constant (equals to $3986005 \times 10^{8} \mathrm{~m}^{3} \mathrm{~s}^{-2}$ in TRS WGS-84 G1150). In this study the TRS WGS-84 G1150 was used, since the GCP, CP and state vectors are referred to it.

In the orientation with the Modified UCL Kepler platform model is necessary the values of $X_{0}, Y_{0}$, $Z_{0}, V_{0 X}, V_{0 Y}$ and $V_{0 Z}$ referring to the instant of the acquisition of the first image line. The HRC images are available with metadata files that contains information of position, velocity and 
attitude angles of the satellite CBERS 2B, for all instants of formation of the image, discretized in 1 second, referenced to the TRS WGS84. The state vectors are provided by GPS (Global Positioning System) on board the satellite or TLE (Two Line Elements) NASA ephemeris. In this way, the values referring to the previous instant closest to the instant of the acquisition of the first line in image were obtained (Table 3). Subsequently, the difference of instant of time was obtained (Table 3 ) and then added to the $t$ value in the platform model (Equations (12)).

In the same way, the values of attitude angles $R_{0}, P_{0}$ and $\Psi_{0}$ were also extracted from metadata file (Table 3). These values did not show any variation in file. Nevertheless, the $d_{1}$ and $d_{2}$ values cannot be considered equals to zero because of the crab movement of the CBERS 2B satellite, as mentioned at the beginning of this item. Thus, these parameters were estimated in the bundle adjustment.

Table 3: State vector and attitude angles of the first line of the image.

\begin{tabular}{c|c|c|c|c|c}
\hline $\mathrm{X}_{0}(\mathrm{~m})$ & $\mathrm{V}_{0 \mathrm{X}}(\mathrm{m} / \mathrm{s})$ & $\mathrm{Y}_{0}(\mathrm{~m})$ & $\mathrm{V}_{\text {or }}(\mathrm{m} / \mathrm{s})$ & $\mathrm{Z}_{0}(\mathrm{~m})$ & $\mathrm{V}_{0 z}(\mathrm{~m} / \mathrm{s})$ \\
\hline 4658116.208 & -2523.933 & -5095195.554 & 316.761 & -1885419.044 & -7115.968 \\
\hline$R_{0}\left(^{\circ}\right)$ & $P_{0}\left(^{\circ}\right)$ & $\Psi_{0}\left(^{\circ}\right)$ & $\begin{array}{c}\text { Instant of time of the } \\
\text { state vector and attitude } \\
\text { angles values (UTC-3h) }\end{array}$ & $\begin{array}{c}\text { Instant of time of } \\
\text { acquisition of the first } \\
\text { image line (UTC-3h) }\end{array}$ & $\begin{array}{c}\text { Difference } \\
\text { in instants } \\
\text { of time }\end{array}$ \\
\hline-1.59466 & 0.108791 & 3.74884 & $13 \mathrm{~h} 34 \mathrm{~m} 54 \mathrm{~s}$ & 13h34m54.369s & $0.369 \mathrm{~s}$ \\
\hline
\end{tabular}

In the adjustments was used the parametric method with weighted constraint. The weights were calculated from the inverse of the estimated variances of the constrained parameters. For the components of the position $\left(X_{0}, Y_{0}, Z_{0}\right)$ and velocity $\left(V_{O X}, V_{O Y}, V_{O Z}\right)$ were considered standard deviations of $3000 \mathrm{~m}$ and $1000 \mathrm{~m} / \mathrm{s}$ respectively. For the attitude angles were considered standard deviations of $4^{\circ}$ as used in Marcato Júnior et al. (2011).

For the case of the polynomial platform model (Equations (10)), before the orientation, the parameters $a_{1}, b_{1}, a_{2}, b_{2}, a_{3}, b_{3}, a_{4}, b_{4}, a_{5}, b_{5}, a_{6}$ and $b_{6}$ were estimated. This was done based on an adjustment of observations of the available state vector in the metadata file using the $2^{\text {nd }}$ order polynomial model. The parameters $a_{9}$ and $b_{9}$ were not estimated previously in this step because the $\psi$ values did not show any variation in metadata file. However, as mentioned, these values cannot be considered equals to zero because of the crab movement of the CBERS 2B satellite. Therefore, the $a_{9}$ and $b_{9}$ parameters were estimated posteriorly in the bundle adjustment. The previously estimated values of the coefficients were showed in Table 4.

Table 4: Estimated values of the polynomial coefficients from the adjustment with the observation of the state vectors available in metadata files.

\begin{tabular}{c|c|c|c|c|c}
\hline$a_{1}(\mathrm{~m} / \mathrm{s})$ & $a_{2}(\mathrm{~m} / \mathrm{s})$ & $a_{3}(\mathrm{~m} / \mathrm{s})$ & $a_{4}\left(\mathrm{~m} / \mathrm{s}^{2}\right)$ & $a_{5}\left(\mathrm{~m} / \mathrm{s}^{2}\right)$ & $a_{6}\left(\mathrm{~m} / \mathrm{s}^{2}\right)$ \\
\hline 2538.3957 & -334.3653 & 7108.2914 & 4.9874 & -5.8869 & -2.0803 \\
\hline$b_{1}\left(\mathrm{~m} / \mathrm{s}^{2}\right)$ & $b_{2}\left(\mathrm{~m} / \mathrm{s}^{2}\right)$ & $b_{3}\left(\mathrm{~m} / \mathrm{s}^{2}\right)$ & $b_{4}\left(\mathrm{~m} / \mathrm{s}^{3}\right)$ & $b_{5}\left(\mathrm{~m} / \mathrm{s}^{3}\right)$ & $b_{6}\left(\mathrm{~m} / \mathrm{s}^{3}\right)$ \\
\hline-0.0519 & 0.0068 & -0.1453 & -0.0001 & 0.0001 & $4.25 \times 10^{-5}$ \\
\hline
\end{tabular}


After the estimates of the coefficients, the same ones were applied in the polynomial model of $2^{\text {nd }}$ order and the parameters $X_{0}, Y_{0}, Z_{0}, V_{0 X}, V_{0 y}$ e $V_{0 z}$ were calculated for the instant of obtaining of the first line of the image. The initial attitude angles were the same as in Table 3 . The values are shown in Table 5.

Table 5: State vectors and attitude angles of the first line of the image in polynomial model.

\begin{tabular}{c|c|c|c|c|c}
\hline$X_{0}(\mathrm{~m})$ & $V_{0 x}(\mathrm{~m} / \mathrm{s})$ & $Y_{0}(\mathrm{~m})$ & $V_{0 Y}(\mathrm{~m} / \mathrm{s})$ & $Z_{0}(\mathrm{~m})$ & $V_{0 z}(\mathrm{~m} / \mathrm{s})$ \\
\hline 4657185.150 & -2525.778 & -5095079.018 & 318.934 & -1888045.020 & -7115.209 \\
\hline \multicolumn{2}{c|}{$R_{0}\left(^{\circ}\right)$} & \multicolumn{2}{|c|}{$P_{0}\left(^{\circ}\right)$} & \multicolumn{2}{c}{$\Psi_{0}\left({ }^{\circ}\right)$} \\
\hline \multicolumn{2}{c|}{-1.59466} & \multicolumn{2}{c|}{0.1087} & \multicolumn{2}{c}{3.74884} \\
\hline
\end{tabular}

Still in the adjustments with the polynomial platform model, on the parameters $X_{0}, Y_{0}, Z_{0}, a_{1}, a_{2}$, $a_{3}, b_{1}, b_{2}$ e $b_{3}$ were applied weighted constraint using the inverse of the estimated variances of these parameters. The standard deviations adopted for the parameters $X_{0}, Y_{0}, Z_{0}$ were $3000 \mathrm{~m}$, $1000 \mathrm{~m} / \mathrm{s}$ for $a_{1}, a_{2}, a_{3}$ and for $b_{1}, b_{2}$ and $b_{3}$ were those estimated in the adjustment of observations of the orbit using the observations of the state vector (Table 6).

Table 6: Standard deviations of parameters $b_{1}, b_{2}$ and $b_{3}$ for the image.

\begin{tabular}{c|c|c}
\hline$\sigma_{b 1}\left(\mathrm{~m} / \mathrm{s}^{2}\right)$ & $\sigma_{b 2}\left(\mathrm{~m} / \mathrm{s}^{2}\right)$ & $\sigma_{b 3}\left(\mathrm{~m} / \mathrm{s}^{2}\right)$ \\
\hline $4.27 \times 10^{-5}$ & $5.14 \times 10^{-5}$ & $2.07 \times 10^{-5}$ \\
\hline
\end{tabular}

As indicated previously in item 2.1 , the parameters $V_{x 0}, a_{4}, b_{4}, V_{y_{0}}, a_{5}, b_{5}, V_{z 0}, a_{6}$ and $b_{6}$ must be fixed in the adjustments of observations for the orientations. In this case, these quantities were considered constant in the models. In Table 7, the parameters that were estimated in each platform model are shown. As can be seen, the proposed model presents less parameters when compared to $2^{\text {nd }}$ order polynomial.

Table 7: Parameters to be estimated in bundle adjustment with the use de each platform model.

\begin{tabular}{c|c}
\hline & Parameters \\
\hline Modified UCL Kepler Model & $X_{0}, Y_{0}, Z_{0}, V_{0 x}, V_{0}, V_{0 z}, R_{0}, P_{0}, \Psi_{0}, d_{1}, d_{2}$ \\
\hline $2^{\text {nd }}$ order polynomial model & $X_{0}, a_{1}, b_{1}, Y_{0}, a_{2}, b_{2}, Z_{0}, a_{3}, b_{3}, R_{0}, P_{0}, \Psi_{0}, a_{9}, b_{9}$ \\
\hline
\end{tabular}

In order to analyse the results of the orientations, the RMSE values were calculated from the discrepancies between the coordinates of the CPS and the coordinates of the corresponding points obtained by the inverse Collinearity Equations. Before this procedure, all the coordinates were transformed to coordinates referred to Local Geodetic System (LGS). In the inverse Collinearity Equations the values considered for the $Z_{L}$ components were the same values of the CPs. Thus, the RMSE values for the LSG components are: 


$$
\begin{aligned}
& R M S E_{X_{L}}=\sqrt{\frac{\sum_{i=1}^{n} \Delta X_{L}^{2}}{n-1}}, \\
& R M S E_{Y_{L}}=\sqrt{\frac{\sum_{i=1}^{n} \Delta Y_{L}^{2}}{n-1}},
\end{aligned}
$$

where $\Delta X_{L}$ and $\Delta Y_{L}$ are the discrepancies in the LSG components $X_{L}$ and $Y_{L}$, and $n$ is the number of used CPs.

\section{Results}

After the orientations using the two platform models and two set of GCPs the results of adjustment were analyzed (Table 8).

Table 8: Results of the adjustments of observations.

\begin{tabular}{c|c|c|c|c}
\hline \multicolumn{2}{c|}{$70 \mathrm{GCPs} / \mathrm{43}$ CPs } & \multicolumn{2}{c}{$35 \mathrm{GCPs} / 43 \mathrm{CPs}$} \\
\hline $\begin{array}{c}\text { Modified UCL Kepler model } \\
\text { (Experiment 1) }\end{array}$ & $\begin{array}{c}\text { Polynomial model } \\
\text { (Experiment 2) }\end{array}$ & $\begin{array}{c}\text { Modified UCL Kepler model } \\
\text { (Experiment 3) }\end{array}$ & \multicolumn{2}{c}{ Polynomial model } \\
(Experiment 4)
\end{tabular}

From the hypothetical tests with the Chi-square distribution, we compared the value of the variances of the unit of weight a priori $\left(\sigma_{0}^{2}\right)$ and a posteriori $\left(\hat{\sigma}_{0}^{2}\right)$, at a confidence level of $95 \%$. It can be seen from Table 8 that the basic hypothesis $\hat{\sigma}_{0}^{2}=\sigma_{0}^{2}$ was accepted at a 95\% confidence level for both orientations using the two different sets of GCPs. It can also be seen from Table 8 that, since the weighting in the observations was 3 pixels $(0.030 \mathrm{~mm})$, the Root Mean Square Error (RMSE) values of the residual components were found to be adequate in all orientations. The larger value of RMSE in $x_{c}$ axis direction may be related to the fact that the functional mathematical model does not consider the misalignment of the CCD chips in the focal plane, as presented in item 2.

To analyze the planimetric accuracy of the orientations with the two GCPs distributions, unique sets of CPs for images 1 and 2 were used. The discrepancies between the coordinates of the checkpoints and the coordinates of the corresponding points obtained by the inverse Collinearity Equations were calculated. From the set of discrepancies the RMSE was calculated for the $X$ and $Y_{L}$ components of the LGS and finally the resulting planimetric RMSE. In the inverse Collinearity 
Equations the values considered for the $Z_{L}$ components were the same values of the checkpoints. The values are shown in Table 9.

Table 9: Planimetric accuracy for the image orientation.

\begin{tabular}{c|c|c|c|c}
\hline & \multicolumn{2}{|c|}{70 GCPs / 43 CPs } & \multicolumn{2}{c}{ 35 GCPs / 43 CPs } \\
\hline & $\begin{array}{c}\text { Modified UCL Kepler } \\
\text { model } \\
\text { (Experiment 1) }\end{array}$ & $\begin{array}{c}\text { Polynomial } \\
\text { model } \\
\text { (Experiment 2) }\end{array}$ & $\begin{array}{c}\text { Modified UCL Kepler } \\
\text { model } \\
\text { (Experiment 3) }\end{array}$ & $\begin{array}{c}\text { Polynomial } \\
\text { model } \\
\text { (Experiment 4) }\end{array}$ \\
\hline RMSE XL (m) & 3.46 & 3.46 & 3.62 & 3.40 \\
\hline RMSE YL (m) & 7.04 & 7.10 & 7.21 & 7.37 \\
\hline $\begin{array}{c}\text { Resulting RMSE } \\
(\mathrm{m})\end{array}$ & 7.84 & 7.90 & 8.07 & 8.11 \\
\hline
\end{tabular}

As can be seen in Table 9, the planimetric accuracies obtained with the two platform models are close in both GCPs distributions. In the first distribution of GCPs, there was a difference of $6 \mathrm{~cm}$ only in the $Y_{L}$ component with the use of the Modified UCL Kepler model and the polynomial model. In the second distribution of GCPS the results in $X_{L}$ and $Y_{L}$ components presented differences of $22 \mathrm{~cm}$ and $16 \mathrm{~cm}$ respectively. It is also observed that the differences of accuracy in the use of the first and second set of GCPs reach a maximum of $23 \mathrm{~cm}$ in the resulting RMSE, being considered practically similar. It should be noted that the distribution of GCPS was satisfactory in both configurations.

Analyzing the resulting planimetric accuracy, the results were practically the same. For the first set of GCPs, there is an improvement of $6 \mathrm{~cm}$ using the Modified UCL Kepler model in relation to the use of the polynomial model. For the second set of GCPs the results showed a difference of 4 $\mathrm{cm}$. It is also noticed that, for the reasons mentioned in item 3 , the accuracy is lower in the $Y_{L}$ component, as expected.

In order to verify the presence of significant trends in the discrepancies, hypothesis tests were performed using the standard Normal distribution $Z \sim N(0,1)$. The confidence level $(1-\alpha)$ adopted was $95 \%$. The tested hypotheses were: $H_{0}: \mu=0$ and $H_{1}: \mu \neq 0$, where $\mu$ is the sample mean. The results are shown in Table 10.

Table 10: Results of the hypothetical tests for the experiments using the image 1.

\begin{tabular}{|c|c|c|c|c|c|c|}
\hline & \multicolumn{3}{|c|}{70 GCPs / 43 CPs } & \multicolumn{3}{|c|}{35 GCPs / 43 CPs } \\
\hline & Comp. $X_{L}$ & Comp. $Y_{L}$ & \multirow{2}{*}{ $\pm Z(1-\alpha / 2)$} & Comp. $X_{L}$ & Comp. $Y_{L}$ & \multirow{2}{*}{ $\pm Z(1-\alpha / 2)$} \\
\hline & $Z$ score & $Z$ score & & $Z$ score & $Z$ score & \\
\hline Modified UCL Kepler model & 1.5701 & 1.1729 & \multirow{2}{*}{ \pm 1.96} & 1.4575 & 1.1924 & \multirow{2}{*}{ \pm 1.96} \\
\hline Polynomial model & 1.5001 & 1.1633 & & 1.4817 & 1.2486 & \\
\hline
\end{tabular}


As can be seen in Table 10 it is noticed that for both $X_{L}$ and $Y_{L}$ components all experiments can be considered free of significant trends at the 95\% 1- $\alpha$ confidence level.

\section{Conclusions}

The aim of this work was to present a novel model to orientation of linear optical satellite image, based in the adaptation of the Orbit-Attitude model for the use of the Modified UCL Kepler platform model. In order to validate the proposed model, experiments were made with one HRC-CBERS 2B image. In the experiments, the differences in terms of the planimetric accuracy resulting in the application of the Modified UCL Kepler model and the polynomial model were small, at most $6 \mathrm{~cm}$ or $2.2 \%$ of the GSD. The differences in planimetric accuracy in the use of different quantities of GCPs in both models were also not significant, reaching a maximum of 24 $\mathrm{cm}$ ( $9 \%$ of the GSD). It should be noted that the distribution of GCPs was satisfactory in both configurations. Another fact observed was that the obtained accuracies in the orientations of the image were higher than 1 GSD in all the experiments ( 3 GSD). It was also verified a lower accuracy in the component $Y_{L}$, possibly caused by the questions presented in item 3.

Although the results obtained with the two models were similar, there are advantages on the usage of the proposed model, such as:

- direct use of ephemeris (components of position and velocity vectors) and attitude angles without interpolation;

- the initial adjustment of the orbit to estimate the polynomial parameters $a_{1}, b_{1}, a_{2}, b_{2}, a_{3}, b_{3}$, $a_{4}, b_{4}, a_{5}, b_{5}, a_{6}$ and $b_{6}$ is unnecessary and;

- decrease in the number of parameters, increase in the number of degrees of freedom in the bundle adjustments and reduction of the minimum quantity of GCPs.

Thus, it is recommended to use the proposed rigorous model for orientations of pushbroom linear optical satellite images. For the case of HRC CBERS 2B images it is recommended the subpixel identification of the image coordinates of the GCPs and CPs, in order to improve the quality of the residues vector.

\section{AUTHOR'S CONTRIBUTION}

Definition of research problem (Tiago Lima Rodrigues), Literature review (Tiago Lima Rodrigues), Definition of methodological procedures (Tiago Lima Rodrigues), Data collection (Marcela do Valle Machado), Data processing (Tiago Lima Rodrigues and Marcela do Valle Machado) Analysis and interpretation of data (Tiago Lima Rodrigues and Marcela do Valle Machado), Manuscript writing (Tiago Lima Rodrigues and Marcela do Valle Machado). 


\section{REFERENCES}

ASTER GDEM Validation Team: METI/ERSDAC/NASA/LPDAAC/USGS/EROS in cooperation with NGA and Other Collaborators. 2009. ASTER Global DEM Validation Summary Report. METI \& NASA.

Bang, K. Woosang, C. 2001. Analysis of EOC Sensor Model. In: FIG Working Week. Seoul, Republic of Korea, 6-11 May 2001.

Carvalho, L. A. S. Strauss, C. Fonseca, L. M. G. 2009. Determinação da resolução efetiva da câmera HRC-CBERS-2B pelo método de espalhamento de borda. In: XIV Simpósio Brasileiro de Sensoriamento Remoto. Natal, Brazil, 25-30 April 2009.

Dowman, I. Michalis, P. 2003. Generic rigorous model for along track stereo satellite sensors. In: ISPRS workshop on High resolution mapping from Space. Hanover, Germany, 4-6 October 2003.

Dowman, I. Michalis, P. Li, L. 2011. Analysis of Urban Landscape Using Multi Sensor Data. In: $4^{\text {th }}$ ALOS PI Symposium. Tokyo, Japan, 15-17 November 2011.

Epiphanio, J. C. N. 2009. CBERS: estado atual e futuro. In: XIV Simpósio Brasileiro de Sensoriamento Remoto. Natal, Brazil, 25-30 April 2009.

Gugan, D. Dowman, I. 1988. Topographic mapping from SPOT imagery. Photogrammetric Engineering \& Remote Sensing, 54 (10), pp.1409-1414.

INPE, 2014. Satélite Sino-Brasileiro de Recursos Terrestres. [online] Available at:< http://www.cbers.inpe.br > [Accessed 13 november 2014].

Jacobsen, K. 2007. Orientation of high resolution optical space images. In: ASPRS 2007 Annual Conference. Tampa, USA, 7-11 May 2007.

Jovanovic, V. M. Smyth, M. M. Zong, J. 1999. MISR Level 1 In-flight Geometric Calibration Algorithm Theoretical Basis. JPL report, code JPL D-13399, Rev. B.

Kim, T. Dowman, I. 2006. Comparison of two physical sensor models for satellite images: Position-Rotation model and Orbit-Attitude model. The Photogrammetric Record, 21(114), pp.110-123.

Leick, A. 2004. GPS Surveying. 3rd ed. New Jersey: John Wiley \& Sons.

Machado e Silva, A. J. F. 2005. Geometria de imagens: do projeto do satélite à geração dos produtos. PhD. Instituto Nacional de Pesquisas Espaciais.

Marcato Junior, J. 2011. Fototriangulação em bloco de imagens orbitais com modelos rigorosos baseados em pontos e retas. PhD. Universidade Estadual Paulista.

Marcato Junior, J. Tommaselli, A. M. G. 2013. Exterior orientation of CBERS-2B imagery using multi-feature control and orbital data. ISPRS Journal of Photogrammetry and Remote Sensing, 79, pp.219-225.

Marcato Junior, J. et al. 2011. Orientação de imagens CBERS-2B usando o modelo rigoroso de colinearidade com dados orbitais. Boletim de Ciências Geodésicas, 17(3), pp.401-416.

Medeiros, N. G. Tommaselli, A. M. G. 2009. Orientação indireta de imagens CBERS: Avaliação de técnicas que usam linhas retas e sua combinação com pontos. Boletim de Ciências Geodésicas, 15(1), pp.33- 57. 
Medeiros, N. G. Tommaselli, A. M. G. Marcato Junior, J. 2009. Orientação exterior de imagens orbitais HRC-CBERS2B com modelo de coplanaridade usando feições retas. In: VI Colóquio Brasileiro de Ciências Geodésicas. Curitiba, Brazil, 3-6 December 2009.

Michalis, P. 2005. Generic rigorous model for along track stereo satellite sensors. PhD. University College London.

Michalis, P. Dowman, I. 2004. A rigorous model and DEM generation for SPOT5-HRS. In: XX ISPRS Congress, Comission I. Istanbul, Turkey, 12-23 July 2004.

Michalis, P. Dowman, I. 2005. A model for along track stereo sensors using rigorous orbit mechanics. International Archives of the Photogrammetry, Remote Sensing and Spatial Information Sciences, 36(1/W1).

Michalis, P. Dowman, I. 2006. An improved model for along-track stereo sensors using rigorous orbit mechanics and navigation data. In: ISPRS Commission I Symposium on From sensors to imagery. Paris, France, 04-06 May 2006.

Michalis, P. Dowman, I. 2008a. A Generic Model for Along Track Stereo Sensors Using Rigorous Orbit Mechanics. Photogrammetric Engineering and Remote Sensing, 74(3), pp.303-309.

Michalis, P. Dowman, I. 2008b. Exterior orientation improved by the coplanarity equation and DEM generation for Cartosat-1. In: XXI ISPRS Congress, Comission I. Beijing, China, 3-11 July 2008.

Michalis, P. Dowman, I. 2010. Noise-Reduction and exterior orientation improvement by the coplanarity equation for ALOS-PRISM. In: $4^{\text {th }}$ ALOS PI Symposium. Tokyo, Japan, 15-17 November 2010.

Orun, A. B. Natarajan, K. 1994. A Modified Bundle Adjustment Software for SPOT Imagery and Photography: Tradeoff. Photogrammetric Engineering and Remote Sensing, 60(12), pp.14311437.

Poli, D. 2005. Modelling of Spaceborne Linear Array Sensors. PhD. Institute of Geodesy and Photogrammetry.

Radhadevi, P. V. Sasikumar, T. P. Ramachandran, R. 1994. Orbit attitude modelling and derivation of ground co-ordinates from spot stereopairs. Journal of Photogrammetry and Remote Sensing, 49(4), pp.22-28.

Rodrigues, T. L. Ferreira, L. D. D. 2013. Aplicação do movimento kepleriano na orientação de imagens HRC - CBERS 2B. Boletim de Ciências Geodésicas, 19(1), pp.114-134.

Rodrigues, T. L. Machado, M. V. Debiasi, P. Mitishita E. A. Damasceno F. D. D. 2016. Calibração geométrica em órbita do sensor HRC-CBERS 2B. Boletim de Ciências Geodésicas, 22(1), pp.108131.

Rodrigues, T. L. et al. 2017. Accuracy Improvements in the Orientation of ALOS PRISM Images Using IOP Estimation and UCL Kepler Platform Model. Remote Sensing, 9(7), pp.634-665.

Seeber, G. 2003. Satellite Geodesy: foundations, methods, and applications. 2nd ed. Berlim: Walter de Gruyter.

Tommaselli, A. M. G. et al., 2009. Avaliação dos resultados da fototriangulação de imagens orbitais coletadas pelo sensor HRC do satélite CBERS-2B. In: VI Colóquio Brasileiro de Ciências Geodésicas. Curitiba, Brazil, 3-6 December 2009. 
Toutin, T. 2004. Geometric processing of Remote Sensing images: models, algorithms and methods. International Journal of Remote Sensing, 25(10), pp.1893-924.

Westin, T. 1990. Precision rectification of SPOT imagery. Photogrammetric Engineering and Remote Sensing, 56(2), pp.247-53. 